\title{
Chromosome 7 Multiplication in EGFR-positive Lung Carcinomas Based on Tissue Microarray Analysis
}

\author{
EVANGELOS TSIAMBAS ${ }^{1,2^{*}}$, NICHOLAS S. MASTRONIKOLIS ${ }^{3 *}$, ALICIA Y. LEFAS ${ }^{4 *}$, \\ STAVROS N. GEORGIANNOS ${ }^{5}$, VASILEIOS RAGOS ${ }^{6 *}$, PANAGIOTIS P. FOTIADES ${ }^{7}$, \\ NIKOLAOS TSOUKALAS ${ }^{8}$, NIKOLAOS KAVANTZAS ${ }^{2}$, ANDREAS KARAMERIS ${ }^{9}$, \\ DIMITRIOS PESCHOS ${ }^{10^{*}}$, EFSTRATIOS PATSOURIS $^{2}$ and KONSTANTINOS SYRIGOS ${ }^{11}$ \\ ${ }^{1}$ Department of IHC \& Molecular Biology, 401 GAH, Athens, Greece; \\ ${ }^{2}$ Department of Pathology, Medical School, University of Athens, Athens, Greece; \\ ${ }^{3}$ Department of ENT, Head and Neck Surgery, Medical School, University of Patras, Patras, Greece; \\ ${ }^{4}$ Faculty of Medicine, University of Southampton, Southampton, U.K.; \\ ${ }^{5}$ Department of Breast Surgery, Blue Cross Hospital Breast Cancer Action Fund, London, U.K.; \\ ${ }^{6}$ Department of Maxillofacial, School of Medicine, University of Ioannina, Ioannina, Greece; \\ ${ }^{7}$ Department of Surgery, Leicester General Hospital, Leicester, U.K.; \\ ${ }^{8}$ Department of Oncology, 417 VA Hospital (NIMTS), Athens, Greece; \\ ${ }^{9}$ Department of Pathology, 417 VA Hospital (NIMTS), Athens, Greece; \\ ${ }^{10}$ Department of Physiology, Medical School, University of Ioannina, Ioannina, Greece; \\ ${ }^{11} 3 r d$ Department of Medicine, Athens School of Medicine, "Sotiria" General Hospital, Athens, Greece
}

\begin{abstract}
Background/Aim: Epidermal growth factor receptor (EGFR) over-activation is observed in significant proportions of non-small cell lung carcinomas (NSCLC). Our aim was to investigate the role of chromosome 7 multiplication with regard to its influence in EGFR expression, combined or not with gene amplification. Materials and Methods: Using tissue microarray technology, fifty $(n=50)$ primary NSCLCs were cored and re-embedded into the final recipient block. Immunohistochemistry (IHC) and also chromogenic in situ hybridization (CISH) were performed. Results: EGFR expression at any level was detected in $40 / 50$ (80\%) cores. Over-expression was observed in 23/40 (57.5\%) cases. Gene amplification was identified in $11 / 50(22 \%)$ cases whereas chromosome 7 polysomy in $8 / 50$ (16\%) cases. Pure chromosome 7 multiplication alone led to low or moderate levels of
\end{abstract}

This article is freely accessible online.

*These Authors contributed equally to this study.

Correspondence to: Dr. Evangelos Tsiambas, 17 Patriarchou Grigoriou E Street, Ag. Paraskevi, 15341 Athens, Greece. Fax: +30 2106526259 , e-mail: tsiambasecyto@yahoo.gr

Key Words: Lung, carcinoma, epidermal growth factor receptor, chromosome, gene, tissue microarray. expression. Overall EGFR expression was correlated with gene $(p=0.001)$ and interestingly with chromosome 7 centromere numerical imbalances $(p=0.004)$. Conclusion: EGFR expression is associated not only with amplification, but also with chromosome 7 centromere multiple copies. Chromosome 7 multiplication -due to centromere region amplification or true polysomy- is critical for applying monoclonal antibody targeted therapeutic strategies excluding the pure non-amplified cases.

Critical genes for regulation of signal transduction to the nucleus are located on chromosome 7. Among them, Epidermal growth factor receptor (EGFR-gene locus: 7p12, exons: 30), MET proto-oncogene, receptor tyrosine kinase (c MET-gene locus: 7q31, exons: 24), and V-raf murine sarcoma viral oncogene homolog BlB-Raf proto-oncogene, serine/threonine kinase ( $B R A F$-gene locus: 7q34, exons: 22 ) are frequently deregulated in solid malignancies including lung, colon and head and neck carcinomas (1-3). Especially in NSCLC, those genes are correlated with established criteria for applying targeted-therapeutic strategies in subgroups of patients characterized predominantly by specific mutations or amplification $(4,5)$. Chromosome 7 deregulation due to aneuploidy/polysomy/monosomy or single/complex gene abnormalities (mutation/amplification) plays a crucial role in those malignancies thus increasing their biological aggressive behavior $(6,7)$. The discovery of novel agents such as glucocorticoid receptor, which regulates 
mitotic progression and its reduced expression is detected in a panel of human liver, lung, prostate, colon, and breast cancers, improves our molecular knowledge in understanding mechanisms that induce chromosomal instability (8).

EGFR gene deregulation mechanisms in lung carcinomas -mainly in adenocarcinoma (LAC) and Squamous cell carcinoma (LSCC) - include mutations and gene amplification in a subset of patients. In addition, lung adenocarcinoma tissues harbor a broad spectrum of genomic rearrangements including predominantly somatic mutations in several oncogenes (9-11). Somatic mutations in exons 18 , 20 and 21 are based on classical amino acid changes, whereas in exon 19 small in-frame deletions and insertions have also been detected. Concerning EGFR numerical alterations detected by fluorescent in situ hybridization (FISH) in NSCLC, high gene copy numbers are found in almost $60 \%$ of the patients $(12,13)$. Moreover, gene amplification leads to EGFR protein over-expression in the corresponding specimens (40-80\%) detected by Immunohistochemistry (IHC) $(14,15)$. Although anti-EGFR monoclonal antibody (mAbs) inhibition strategies in NSCLC patients are under consideration, the gene amplification mechanism is the critical molecular event as it happens in HER2 gene amplified depended breast cancers cases (16-18).

In the current study we explored the role of gene and chromosome 7 numerical alterations in LAC and LSCCs associating with the EGFR protein expression in them.

\section{Materials and Methods}

Patients and corresponding tissues. We obtained, for the purposes of our study, fifty $(n=50)$ formalin-fixed paraffin-embedded archival tissue samples of histologically proven NSCLC including fifteen $(n=15)$ lung adenocarcinomas (LAC) and thirty-five $(n=35)$ Lung squamous cell carcinomas (LSCC). The Department of Pathology, 417 VA Hospital, Athens, Greece provided the corresponding tissue blocks for specific protein and molecular analyses. The current research on human paraffin-embedded tissues complied with the principles laid down in the Declaration of Helsinki. Most of them were initially diagnosed by the performance of CT guided Fine needle aspiration (FNA), using conventional and liquid-based cytological methods. All corresponding Hematoxylin and Eosin (H\&E) stained slides were reviewed by two pathologists for confirmation of diagnosis and classified according to World Health Organization (WHO) grading and staging (TNM system) criteria for lung cancer (revised 2014). The tissue samples correspond to 41 male (Range $=47-67$ years) and 9 female (Range $=51-72$ years) patients. Clinicopathological data are demonstrated in Table I.

Tissue microarray construction. Areas of interest were identified in H\&E stained slides by light microscopy (Olympus BX-50, Melville, NY, USA). Selection of those areas was performed on the basis of tumor sufficiency and accurate histological confirmation, avoiding sites of necrosis or bleeding. The corresponding paraffin blocks were obtained for the construction of one TMA block. Using ATA100 apparatus (Chemicon International, Temecula, CA, USA), the entire source blocks were cored one or two times (in order to secure the presence of each case in the final block) and 1-mm diameter tissue cylindrical cores were transferred from each conventional donor block to the recipient block. The final constructed TMA block contained 65 cores of tissue cylindrical specimens, including five cores of the control group (normal appearing lung epithelia). After $3 \mathrm{~mm}$ microtome sectioning and H\&E staining, we observed microscopically that all examined cases were represented by at least one (37 cases) or two tissue spot (13 cases)-confirmation of the adequacy of specimens (Figure 1).

Antibodies and probes. Ready-to-use EGFR monoclonal mouse antibody (clone 31G7-Zymed/Invitrogen, San Fransisco, USA) recognizing predominantly the extracellular domain of EGFR protein, not reacting with other erbB receptors was used. EGFR gene status was determined by applying the ready to use SPOT LIGHT EGFR DNA Probe (Zymed/InVitrogen, San Fransisco, USA). This digoxygenin-labeled probe is located on $7 \mathrm{p} 12$ and covers the entire EGFR gene area. Chromosome 7 status was determined by the ready to use biotin labeled chromosome 7 centromeric probe (Zymed/ InVitrogen, San Fransisco, USA) recognizing the specific repetitive centromeric DNA sequences known as satellite DNA.

Immunohistochemistry (IHC). As described above, the IHC procedure for EGFR antigen was carried out on $3 \mu \mathrm{m}$ serial paraffin sections of TMA block. The corresponding slide was deparaffinized and rehydrated. It was also enzyme digested (proteinase $\mathrm{K}$ ) for 10 min at $37{ }^{\circ} \mathrm{C}$. The NBA kit (Zymed/InVitrogen, San Fransisco, U.S.A) was used for the following detection steps. Blocking solution was applied to the slides for $10 \mathrm{~min}$, followed by incubation for $1 \mathrm{~h}$ using the EGFR monoclonal antibody (dilution $1: 10$ ) at room temperature. Following incubation with the secondary antibody for $10 \mathrm{~min}$, diaminobenzidinetetrahydrocloride (DAB) $(0.03 \%)$ containing $0.1 \%$ hydrogen peroxide was applied as a chromogen and incubated for $5 \mathrm{~min}$. Sections were counterstained, dehydrated and cover-slipped. For negative control slides, the primary antibody was omitted. IHC protocol was implemented by the use of an automated staining system (I 6000 - Biogenex, San Ramon, CA, USA). Membranous and sub-membranous cytoplasmic staining was considered acceptable for the marker, according to manufacturer's data sheet (Figure 2). Colon cancer tissue sections overexpressing EGFR and normal appearing colon and lung epithelia were used as positive and negative controls respectively. EGFR protein expression levels were evaluated semi-quantitatively by using Zymed's Evaluation Guidelines. According to the scoring guidelines, the examined cases were classified as follows: Score 0: no staining or membrane staining in $<10 \%$ of tumor cells; Score $1+$ : faint membrane staining in $>10 \%$ of tumor cells; Score $2+$ : weak or moderate complete membrane staining in $>10 \%$ of tumor cells and Score 3+: strong, complete membrane staining in $>10 \%$ of tumor cells. Scores of 0 and $1+$ were considered as negative for EGFR expression while Scores $2+$ and $3+$ as positive (over expression).

Chromogenic in situ hybridization (CISH). CISH SPOT-Light Chromogenic ISH Detection Kit was applied (Zymed/Invitrogen, San Fransisco, USA). CISH for chromosome 7 status and EGFR gene analysis was performed on $5 \mu \mathrm{m}$ thick paraffin serial sections of the TMA block described above. Two slides were incubated at $37^{\circ} \mathrm{C}$ overnight followed by a $2 \mathrm{~h}$ incubation at $60^{\circ} \mathrm{C}$. They were then 
deparaffinized in xylene for $5 \mathrm{~min}$ twice, and in ethanol for $3 \mathrm{~min}$ thrice. The slides were rinsed in deionised water and then placed in a coplin jar containing CISH FFPE Pretreatment Buffer (CISH Tissue Pre-treatment Kit, Zymed /Invitrogen, San Fransisco, USA). For heat pre-treatment, the coplin jar was capped, loosely screwed, placed in a pressure cooker and timed for $10 \mathrm{~min}$ after the pressure built up. The slides were then immediately washed in deionised water followed by enzyme digestion, which was performed by covering the sections with pepsin (CISH Tissue Pre-treatment Kit, Zymed/Invitrogen, San Fransisco, USA) for $5 \mathrm{~min}$ at $37^{\circ} \mathrm{C}$. The slides were washed with deionised water, dehydrated with graded ethanol and air-dried. Ready to use dig-labeled EGFR gene and a biotin-labeled chromosome 7 centromere probe was applied to each section, respectively. Twenty $(n=20)$ microliters of probe were applied to each of the TMA sections. The CISH Polymer and the Horseradish (HRP) Detection Kit (Zymed/Invitrogen, San Fransisco, USA) - containing similar steps to IHC - were used. Shortly, afterwards TMA sections were placed in 3\% hydrogen peroxide $\left(\mathrm{H}_{2} \mathrm{O}_{2}\right)$ and diluted with methanol for 10 min to block endogenous peroxidase. To block unspecific staining, Cas BlockTM (Zymed/InVitrogen, San Fransisco, USA) was applied and incubated for $10 \mathrm{~min}$. TMA sections were lightly counterstained with hematoxylin and dehydrated in graded ethanol. At the end of the process, CISH centromere signals or gene copies were easily visualized as dark brown/blue scatters or in small clustered dots, using a conventional, bright-field microscopy (Figure 1b). Interpretation of EGFR gene and chromosome 7 centromere signal results was based on Zymed's Evaluation Chart for CISH. According to this guide, two gene copies per nucleus demonstrate normal EGFR gene pattern, whereas 6-10 or small clusters characterize low-level gene amplification. In this case, chromosome 7 status must be evaluated to exclude aneuploidy (3-5 centromeric signals per nucleus; diploid pattern demonstrates normal chromosome status). Finally, high gene amplification level is confirmed by the presence of more than 10 gene copies or large clusters of them per nucleus in more than $50 \%$ of the examined cells (Figure 3 ).

Statistical analysis. Associations between variables including protein expression levels, chromosome and gene signals and pathological parameters were performed by the application of Chisquare $\left(\chi^{2}\right)$ test and Kendall's tau-b coefficient. Two-tailed $p$-values $\leq 0.05$ were considered statistically significant. Results and correlations ( $p$-values) are described in Table II.

\section{Results}

IHC and CISH results were successfully obtained from all analyzed NSCLC cases. EGFR protein expression at any level was detected in $40 / 50(80 \%)$ cores. EGFR over expression (score: $2+/ 3+$ ) was observed in 23/40 (57\%) cases. The rest $(n=17 / 40)$ demonstrated low (score: $1+$ ) expression. Concerning histological type, protein overexpression was observed in 9/15 LACs, and in 14/50 LSCCs. Ten out of the fifty $(n=10 / 50)$ cases were negative (score: 0$)$ for the marker. Gene amplification was identified in 11/50 (22\%) cases whilst chromosome 7 centromeric multiple copies were detected in $8 / 50(16 \%)$ cases. In three tissue cores $(n=3)$, gene amplification was also co-detected. Concerning the rest of the samples $(n=5)$, pure chromosome 7 multiplication alone led to low or moderate levels of expression $(2+, 1+)$. EGFR overall expression was significantly correlated with gene and interestingly also marginally with centromeric chromosome 7 numerical imbalances ( $p=0.001, p=0.004$, respectively). No other statistically significant associations were identified regarding IHC/CISH analyses and histological type, gender or tumor localization. The combined IHC and CISH results are presented in Table II and also in the histogramic demonstrations (Figure 4).

\section{Discussion}

The molecular landscape and also epidemiology of lung cancer is a very promising field of research in the era of targeted therapeutic strategies (19). Genetic susceptibility to EGFR mutations seems to be correlated with different genetic polymorphisms. There are at least three polymorphisms within the EGFR gene. CA-SSR1 (CA simple sequence repeat 1 ) is located in intron 1 and the number of $\mathrm{CA}$ repeats ranges from 14 to 22, with 16 being the most common number of repeats (20). East Asians tend to have longer repeats. Shorter repeats are associated with increased transcription and protein expression $(21,22)$. Two single nucleotide polymorphisms (SNPs) in the promoter region with effects on increased transcription and expression of EGFR mRNA have also been identified. However, both of these SNPs (-216G/T, -191C/A) are less common in East Asians (23). Similarly, another crucial agent is tobacco consumption and its influence in activating the carcinogenetic mechanism leading to lung cancer. But in contrast to this, EGFR mutations are more frequent among non-smokers. In fact, many studies have shown that the risk of the aforementioned resulting lung cancer is independent of smoking as exemplified by those with EGFR mutations not being affected by smoking dose, and the fact that East Asians have a higher risk for this type of lung cancer than Caucasians. In contrast, smoking related lung cancer increases with smoking dose (24-26). Caucasians are more susceptible to this type of lung cancer based on epidemiological data.

Expression of EGFR is deregulated in a variety of solid tumors and has been correlated with disease progression and poor survival (27). In 34-84\% of NSCLC patients, EGFR overexpression is also detectable; an increased expression of EGFR is proposed to be of prognostic and also of potential predictive relevance (28). High EGFR gene copy numbers are found in almost $60 \%$ of the patients (29). Based on its central role in cellular tumor growth, EGFR is intended as a favored drug target for the development of specific antiNSCLC treatments (30). A great number of EGFR specific therapeutics has been developed and tested in clinical trials; including specific antibodies such as cetuximab and 
necitumumab, as well as small-molecule tyrosine kinase inhibitors (TKI) like erlotinib, afatinib, and gefitinib (31). The identification of patients who might benefit from these selective drugs is of tremendous interest. Although EGFR targeted therapies have been approved, there exists no general consensus concerning the evaluation of EGFR expression patterns in NSCLC (32).

In the current study, we analyzed the EGFR at the protein (IHC) and also at the gene (CISH) level combined with chromosome 7 numerical imbalances. According to our findings, EGFR overexpression (score: $2+/ 3+$ ) was observed in a significant proportion of the examined cases. Gene amplification (low to high) and chromosome 7 multiplicity was detected in specific subgroups of examined cases. In three cases $(n=3)$, gene amplification was also detected. Overall EGFR expression was significantly correlated with gene and interestingly also with chromosome 7 centromere numerical imbalances. Our results indicate that EGFR expression levels are associated not only with amplification, but also with chromosome 7 multiple signals in some low or overexpressed cases. Several protein and molecular studies have shown that EGFR expression is related to the gene amplification mechanism, but the role of chromosome 7 multiplication is under consideration (33). The significance of the assessment of EGFR gene copy number and EGFR protein expression as biomarkers to predict therapy responders as well as the selection of patients who might potentially benefit from EGFR targeted therapies was demonstrated by different studies $(34,35)$. In fact, data for the relationship between EGFR expression on the protein level and response to EGFR specific therapies is inconsistent (36). Nevertheless, an increased EGFR gene copy number has recently been proposed as a predictor of anti-EGFR targeted therapies in lung cancer patients (37). The evaluation of EGFR gene status by FISH is delicate: EGFR gene variations in tumor cells are focal and low levels of EGFR amplification are difficult to visualize. Based on this technique there are controversial results regarding the frequency of EGFR FISHpositive and also over expressed cases in LAC and LSCC cases. In some studies, FISH positivity occurred more frequently in LAC than in LSCC, but differences did not reach statistical significance combined with c MET activation (38). In another study EGFR over-expression occurred most frequently in the acinar subtype, followed by the papillary and solid subtypes (39).

In addition to $E G F R$ gene numerical imbalances, especially amplification- chromosome 7 multiplication or true polysomy based not only on FISH/CISH but also on comparative genomic hybridization $(\mathrm{CGH})$ or similar molecular methods - is also critical for handling patients with lung cancer by applying monoclonal antibody targeted therapeutic strategies. With the embedded knowledge and experience regarding breast cancer Chromosome 17
Table I. Clinicopathological data of the examined cases

\begin{tabular}{lc}
\hline & $\mathrm{n}=50$ \\
\hline Gender & \\
Male & 41 \\
Female & 9 \\
Histology & \\
LAC & 15 \\
LSCC & 35 \\
Grade & \\
1 & 8 \\
2 & 29 \\
3 & 13 \\
Stage & \\
I & 8 \\
II & 11 \\
III & 23 \\
IV & 8 \\
Smoking status & \\
Non & 6 \\
Active & 37 \\
Former & 7 \\
\hline
\end{tabular}

LAC: Lung adenocarcinoma; LSCC: Lung squamous cell carcinoma.

instability, some molecular studies suggest that in growth factor receptors (i.e. HER2, EGFR, c-MET) protein overexpression is mainly correlated with gene amplification but in a subset of cases also with polysomy or multiplication (40). Polysomy implies that the number of a particular chromosome is greater than diploid and it has been represented by $\geq 3$ signals in FISH assays with a probe targeted to the centromeric area of the particular chromosome. Recent studies reported that chromosome 17 polysomic cases defined by multiplication of CEP17 in FISH assays were frequently related to $17 \mathrm{q}$ gain involving centromeres or amplification of the centromeric region rather than whole chromosome multiplication (true chromosome 17 polysomy). A study group reported that only one of 18 CEP17 polysomic cases (increased copy number of CEP17 by FISH) was true chromosome 17 polysomy by microarraybased comparative genomic hybridization and FISH for HER2 (17q12), CEP17, SMS (17p11.2), and RARA (17q21.2). Therefore, CEP17 multiplication by in situ hybridization does not indicate true chromosomal 17 polysomy in all cases $(41,42)$.

\section{Conclusion}

In conclusion, EGFR over-expression occurs frequently in NSCLC patients. Based on our results, EGFR expression levels are associated not only with amplification, but marginally also with chromosome 7 centromere multiple 


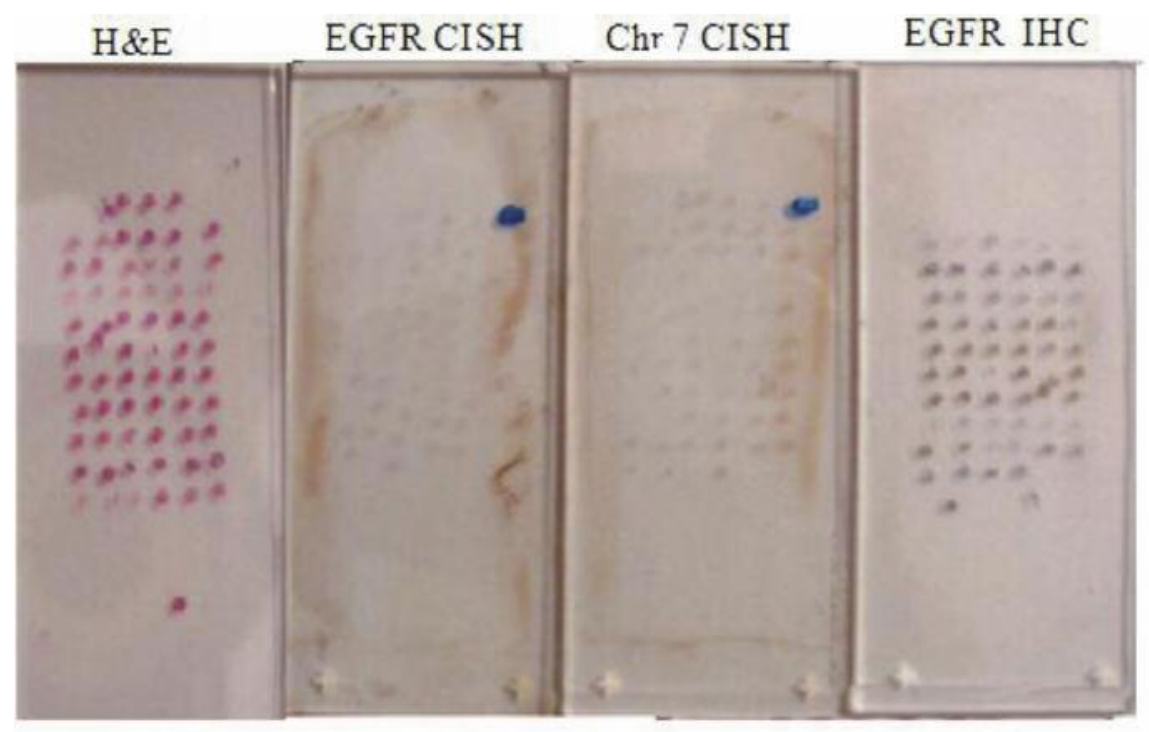

Figure 1. The set of slides including the tissue cores of the examined lung carcinoma cases.
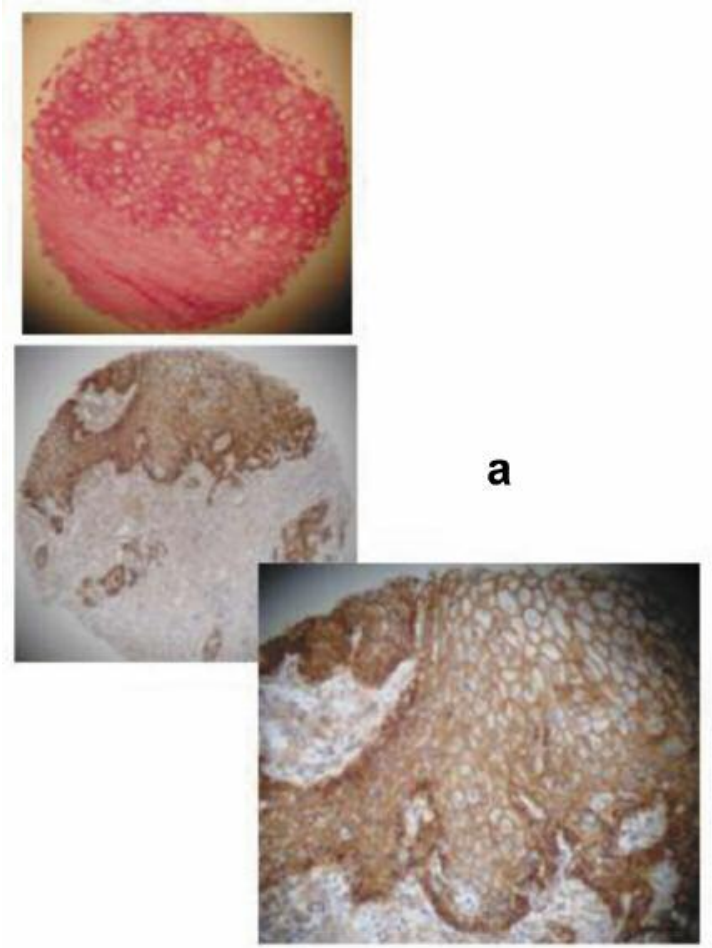

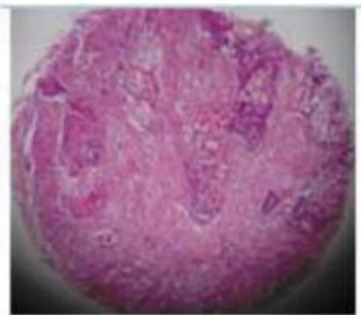

b

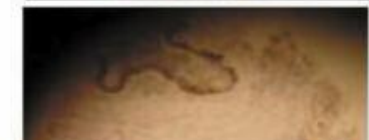

b

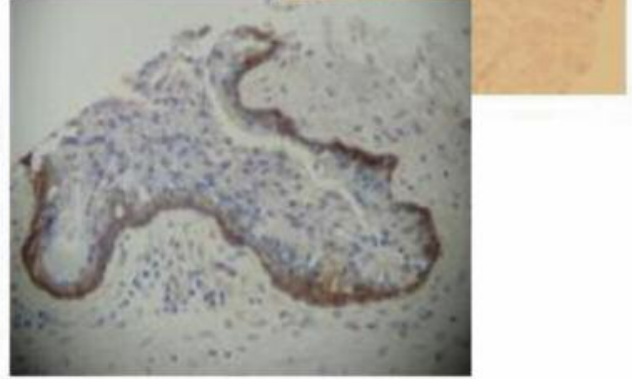

Figure 2. EGFR protein over-expression of two cases: left LSCC and right LAC. Note the dense brown staining pattern in the corresponding cancerous epithelia (H\&E, EGFR DAB staining, original magnification 100x, 400x).

signals. The predominant mechanism in the development of LAC EGFR overexpression is gene amplification. Regarding lung cancer, chromosome 7 numerical imbalances as true polysomy or CEP 7 multiplication are crucial genetic events that modify the protein expression of EGFR, in some cases independently of EGFR gene amplification (43). 


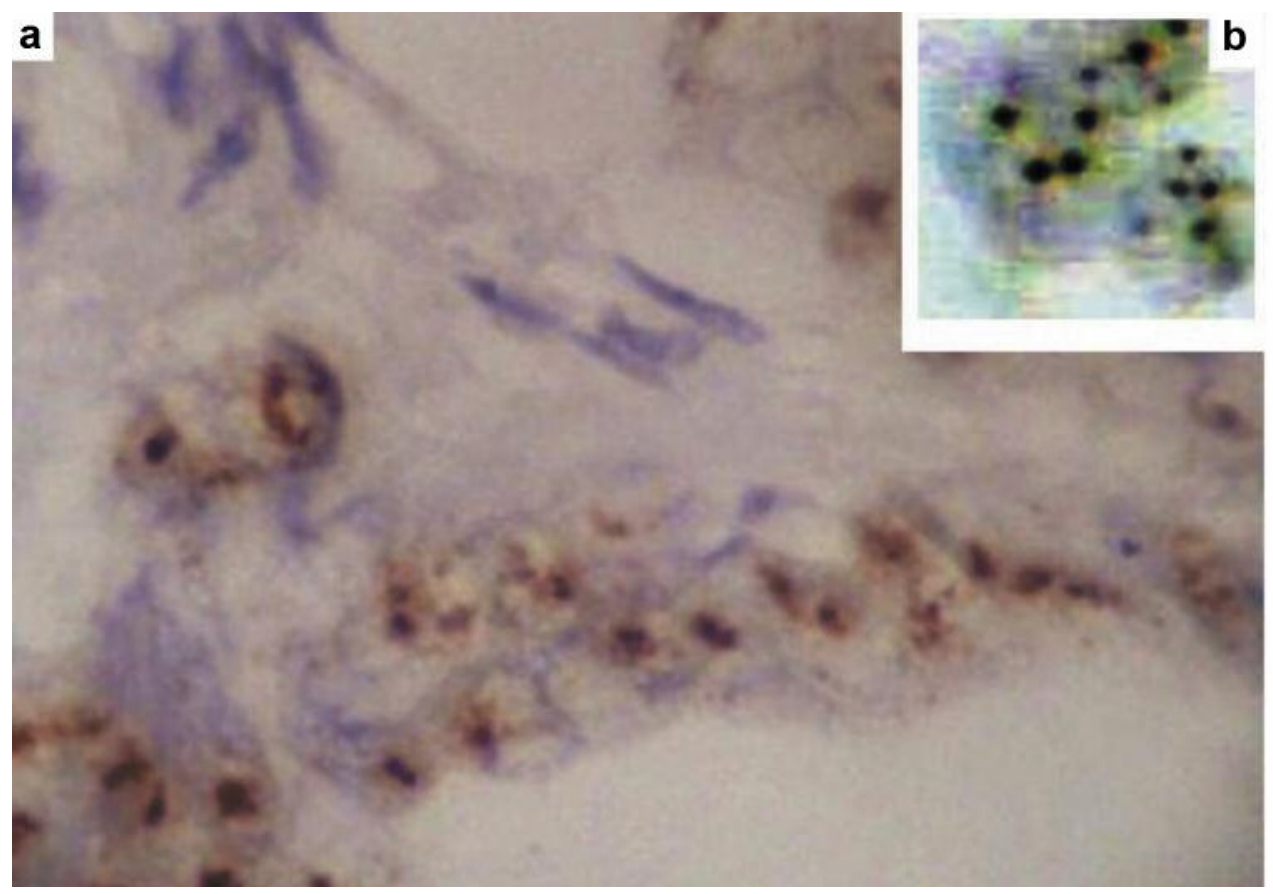

Figure 3. CISH analysis in lung carcinoma cores a. EGFR gene amplification, $b$. chromosome 7 polysomy. Note multiple gene copies as clusters and also chromosome copies inside the corresponding nuclei, respectively (original magnification 400×).
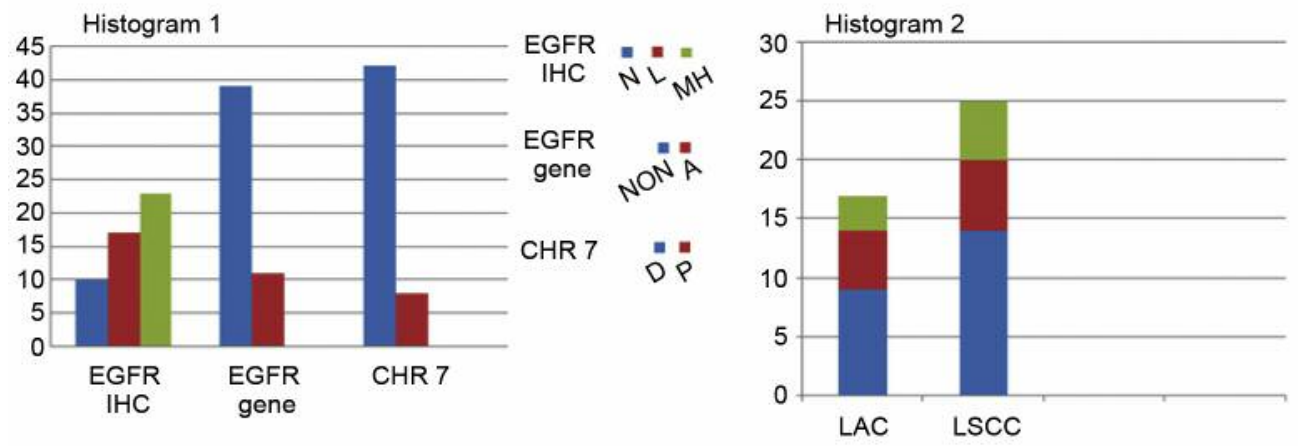

- $\mathrm{CHR} 7 \mathrm{CISH}$ polysomy/multiplication

- EGFR CISH amplification

- IHC positive

Figure 4. Histogram 1. Combined EGFR IHC/CISH and Chr 7 CISH results in the examined carcinomas, Histogram 2. Comparative combined EGFR IHC/CISH and Chr 7 CISH results in the examined LACs and LSSCs.

Table II. Combined EGFR IHC and EGFR/Chromosome 7 CISH results.

\begin{tabular}{lccccc}
\hline & \multicolumn{2}{c}{ EGFR CISH } & $p$-Value & & \multicolumn{2}{c}{ Chr 7 CISH } \\
\cline { 2 - 3 } & Amplified & Non-amplified & & Diploid & Multiple copies \\
\hline EGFR IHC & 0 & 10 & 0.001 & & 0 \\
0 & 0 & 17 & & 10 & 2 \\
$1+$ & 11 & 12 & & 17 & 6 \\
$2+/ 3+$ & & & 15 & 0.004 \\
\hline
\end{tabular}

CISH: Chromogenic in situ hybridization; IHC: immunohistochemistry; 2+/3+: EGFR protein over-expression (9/15 LAC, 14/50 LSCC). Multiple copies in chromosome 7 analysis: due to pure polysomy or centromere region amplification. 


\section{Conflicts of Interest}

The authors declare no conflicts of interest.

\section{Acknowledgements}

The authors would like to thank George Vilaras' technical support in the field of IHC and CISH analysis, and Mrs. D. Tatsiou, MSc, for providing the statistical analysis.This research was partially supported by the Breast Cancer Action Fund, London, UK.

\section{References}

1 Albertson DG, Collins C, McCormick F and Gray JW: Chromosome aberrations in solid tumours. Nat Genet 34: 36976, 2003.

2 Stratton MR, Campbell PJ and Futreall AP: The cancer genome. Nature 458: 719-724, 2009.

3 Tsiambas E, Ragos V, Lefas AY, Georgiannos SN, Grapsa D, Patsouris E and Syrigos K: Chromosome 7 deregulation in nonsmall cell lung carcinoma molecular landscape. J BUON 20: 1635-1639, 2015.

4 Sasaki H, Maekawa M, and Tatematsu T: Increased BRAF copy number in lung adenocarcinoma. Oncol Lett 9: 709-712, 2015.

5 Lynch TJ, Bell DW and Sordella R: Activating mutations in the epidermal growth factor receptor underlying responsiveness of non-small-cell lung cancer to gefitinib. N Engl J Med 350: 212939, 2004.

6 Varella-Garcia M: Chromosomal and genomic changes in lung cancer. Cell Adhes Migr 4: 100-106, 2009.

7 Weir BA, Woo MS and Getz G: Characterizing the cancer genome in lung adenocarcinoma. Nature 450: 893-898, 2007.

8 Matthews LC, Berrya AA and Morgan DJ: Glucocorticoid receptor regulates accurate chromosome segregation and is associated with malignancy. PNAS 112: 5479-5484, 2015.

9 Khool C, Rogers TM and Fellowes A: Molecular methods for somatic mutation testing in lung adenocarcinoma: EGFR and beyond. Transl Lung Cancer Res 4: 126-141, 2015.

10 Lee JK, Hahn S and Kim DW: Epidermal growth factor receptor tyrosine kinase inhibitors vs conventional chemotherapy in nonsmall cell lung cancer harboring wild-type epidermal growth factor receptor: a metaanalysis. JAMA 311: 1430-1437, 2014.

11 Paez JG, Jänne PA and Lee JC: EGFR mutations in lung cancer: correlation with clinical response to gefitinib therapy. Science 304: 1497-1500, 2004.

12 Han SW, Kim TY and Hwang PG: Predictive and prognostic impact of epidermal growth factor receptor mutation in nonsmall-cell lung cancer patients treated with gefitinib. J Clin Oncol 23: 2493-2501, 2005.

13 Kosaka T, Yatabe Y and Endoh H: Mutations of the epidermal growth factor receptor gene in lung cancer: biological and clinical implications. Cancer Res 64: 8919-8923, 2004.

14 Li T, Kung HJ, Mack PC and Gadara DR: Genotyping and genomic profil $\neg$ ing of non-small-cell lung cancer: implications for current and future therapies. J Clin Oncol 31: 1039-1049, 2013.

15 Yu HA, Riely GJ and Lovly CM: Therapeutic Strategies Utilized in the Setting of Acquired Resistance to EGFR Tyrosine Kinase Inhibitors. Clin Cancer Res 20: 5898-5907, 2014.
16 Tsiambas E, Ragos V and Grapsa D: Chromosomes 7/17 multiplication vs true polysomy: a crucial issue in lung and breast EGFR/HER2 dependent carcinoma cases. J BUON 21: 752-753, 2016.

17 Varshney D, Zhou YY and Geller SA: Determination of HER- 2 status and chromosome 17 polysomy in breast carcinomas comparing HercepTest and PathVysion FISH assay. Am J Clin Pathol 121: 70-77, 2004.

18 Bilous M, Morey A and Armes J: Chromogenic in situ hybridization testing for HER2 gene amplification in breast cancer produces highly reproducible results concordant with fluorescence in situ hybridisation and immunohistochemistry. Pathology 38: 120-124, 2006.

19 Tsiambas E, Lefas AY and Georgiannos SN: EGFR gene deregulation mechanisms in lung adenocarcinoma: A molecular review. Pathol Res Pract 212: 672-677, 2016.

20 Liu W, Innocenti F and Chen P: Interethnic difference in the allelic distribution of human epidermal growth factor receptor intron 1 polymorphism. Clin Cancer Res 9: 1009-1012, 2003.

21 Buerger H, Gebhardt F and Schmidt H: Length and loss of heterozygosity of an intron 1 polymorphic sequence of egfr is related to cytogenetic alterations and epithelial growth factor receptor expression. Cancer Res 60: 854-857, 2000.

22 Liu W, Innocenti $\mathrm{F}$ and $\mathrm{Wu} \mathrm{MH}$ : A functional common polymorphism in a Sp1 recognition site of the epidermal growth factor receptor gene promoter. Cancer Res 65: 46-53, 2005.

23 Mitsudomi T: Molecular epidemiology of lung cancer and geographic variations with special reference to EGFR mutations. Transl Lung Cancer Res 3: 205-211, 2014.

24 Thun MJ, Hannan LM and Adams-Campbell LL: Lung cancer occurrence in never-smokers: an analysis of 13 cohorts and 22 cancer registry studies. PLoS Med 5: e185-189, 2008.

$25 \mathrm{Kim} \mathrm{HR}$, Cho BC and Shim HS: Prediction for response duration to epidermal growth factor receptor-tyrosine kinase inhibitors in EGFR mutated never smoker lung adenocarcinoma. Lung Cancer 83: 374-382, 2014.

26 Sun JM, Ahn MJ and Choi YL: Clinical implications of T790M mutation in patients with acquired resistance to EGFR tyrosine kinase inhibitors. Lung Cancer 82: 294-298, 2013.

27 Hirsch FR, Dziadziuszko R and Thatcher N: Epidermal growth factor receptor immunohistochemistry: comparison of antibodies and cutoff points to predict benefit from gefitinib in a phase 3 placebo-controlled study in advanced nonsmall-cell lung cancer. Cancer 112: 1114-1121, 2008.

$28 \mathrm{Li} \mathrm{AR}$, Chitale D and Riely GJ: EGFR mutations in lung adenocarcinomas: clinical testing experience and relationship to EGFR gene copy number and immunohistochemical expression. J Mol Diagn 10: 242-248, 2008.

29 Hirsch FR, Varella-Garcia M and Cappuzzo F: Combination of EGFR gene copy number and protein expression predicts outcome for advanced non-small-cell lung cancer patients treated with gefitinib. Annals Oncol 18: 752-760, 2007.

30 Sequist LV, Martins RG and Spigel D: First-line gefitinib in patients with advanced non-small-cell lung cancer harboring somatic EGFR mutations. J Clin Oncol 26: 2442-2449, 2008.

31 Antonicelli A, Cafarotti S and Indini A: EGFR-targeted therapy for non-small cell lung cancer: focus on EGFR oncogenic mutation. Int J Med Sci 10: 320-330, 2013.

32 Lee HJ, Xu X and Choe G: Protein overexpression and gene amplification of epidermal growth factor receptor in nonsmall 
cell lung carcinomas: Comparison of four commercially available antibodies by immunohistochemistry and fluorescence in situ hybridization study. Lung Cancer 68: 375-382, 2010.

33 Gaber R, Watermann I, Kugler C and Reinmuth N: Correlation of EGFR expression, gene copy number and clinicopathological status in NSCLC. Diagn Pathol 9: 165-179, 2014.

34 Dacic S, Flanagan M and Cieply K: Significance of EGFR protein expression and gene amplification in non-small cell lung carcinoma. Am J Clin Pathol 125: 860-865, 2006.

35 Hynes NE and Lane HA: ERBB receptors and cancer: the complexity of targeted inhibitors. Nat Rev Cancer 5: 341-354, 2005.

36 Costa DB, Schumer ST and Tenen DG: Differential responses to erlotinib in epidermal growth factor receptor (EGFR)-mutated lung cancers with acquired resistance to gefitinib carrying the L747S or T790M secondary mutations. J Clin Oncol 26: 1182$1184,2008$.

37 Hata A, Katakami N and Yoshioka H: Rebiopsy of nonsmall cell lung cancer patients with acquired resistance to Epidermal growth factor receptor-tyrosine kinase inhibitor: Comparison between T790M mutation-positive and mutation-negative populations. Cancer 119: 4325-4332, 2013.

38 Benedettini E, Sholl LM and Peyton M: Met activation in nonsmall cell lung cancer is associated with de novo resistance to EGFR inhibitors and the development of brain metastasis. Am J Pathol 177: 415-423, 2010.
39 De Oliveira Duarte Achcar R, Nikiforova MN and Yousem SA: Micropappillary lung adenocarcinoma: EGFR, $\mathrm{K}$ ras, and BRAF mutational profile. Am J Clin Pathol 131: 694-700, 2009.

40 Viale G: Be precise! The need to consider the mechanisms for CEP17 copy number changes in breast cancer. J Pathol 219: 12, 2009.

41 Yeh IT, Martin MA and Robetorye RS: Clinical validation of an array CGH test for HER2 status in breast cancer reveals that polysomy 17 is a rare event. Mod Pathol 22: 1169-1175, 2009.

42 Casorzo L, Corigliano M, Ferrero P, Venesio T and Risio M: Evaluation of $7 \mathrm{q} 31$ region improves the accuracy of EGFR FISH assay in non small cell lung cancer. Diagn Pathol 4: 36-40, 2009.

43 Sholl LM, Iafrate A and Chou YP: Validation of chromogenic in situ hybridization for detection of EGFR copy number amplification in non small cell lung carcinoma. Mod Pathol 20: 1028-1035, 2007. 